\title{
Arte y trabajo. La dimensión política del trabajo escénico organizado en Cooperativas de Trabajo Artístico en Uruguay ${ }^{1}$
}

\author{
Art and Work. The political dimention of escenic work organized in Artistic \\ Work Cooperatives in Uruguay
}

\author{
Arte e trabalho. A dimensão política do trabalho cênico organizado em \\ Cooperativas de Trabalho Artístico no Uruguai
}

Itzel Ibargoyen ${ }^{2}$

\section{Resumen}

\begin{abstract}
En el año 2008, se promulgó por el gobierno del Frente Amplio, la ley 18.384 de conformación de las Cooperativas de Trabajo Artístico en Uruguay lo que dio lugar a la creación de Valorarte, una cooperativa de trabajo que nuclea a artistas escénicos del teatro y la danza. Desde un abordaje cualitativo de carácter exploratorio, el objetivo de este trabajo es examinar las características de las reivindicaciones colectivas y defensas de intereses comunes en torno al trabajo en esta cooperativa. A partir de entrevistas, se analizan las problemáticas laborales artísticas en una dimensión contradictoria: como posibles conflictos anticapitalistas ligados a las luchas contra el trabajo características de las vanguardias artísticas del siglo XX que hoy se reactualizan en la posibilidad del trabajo autónomo como liberación del trabajo; o la equiparación de la producción cultural con cualquier tipo de producción, posible de ser regulada bajo el paradigma del trabajo asalariado clásico en el marco del modelo de producción postfordista actual. Se presenta una síntesis de las concepciones sobre el trabajo y la organización colectiva de los integrantes de la cooperativa discutiendo la ambigüedad entre liberación y regulación del trabajo artístico, y las consecuencias de la acción colectiva sostenidas sobre una u otra concepción.
\end{abstract}

Palabras clave: autonomía; cooperativas; trabajo artístico.

\begin{abstract}
In 2008 the Frente Amplio administration approved the 18.384 law for the conformation of Artistic Work Cooperatives in Uruguay which in turn allowed the creation of Valorarte, a cooperative for dance and theater artists. From an exploratory and qualitative perspective the aim of this paper is to examine the characteristics of collective claims and the defense of common interests around labour in this cooperative. The cultural work problematics are analyzed from interviews in a contradictory dimension: as possible anticapitalist conflicts tied to the artistic vanguard struggles against work in XX century; or the matching of cultural production with any type of production, subject of being regulated under the classic wage labour paradigm framed in the actual postfordist production model. A synthesis of work and organization conceptions of the members of the cooperative is presented. The ambigüity between artistic work liberation and regulation and the consequences over collective action are discussed.
\end{abstract}

\footnotetext{
${ }^{1}$ El presente trabajo es un avance de la investigación de maestría "El abismo de la autonomía. Organización laboral y producción cultural en Uruguay, el caso de las Cooperativas de Trabajo Artístico" realizada en el marco de la financiación del programa de Iniciación a la investigación de la Comisión Sectorial de Investigación Científica, Facultad de Ciencias Sociales, Universidad de la República, 2017-2020.

2 Maestranda en Sociología, Facultad de Ciencias Sociales, Universidad de la República. itzel.ibargoyen@gmail.com
} 
Keywords: autonomy; cooperatives; cultural work.

\section{Resumo}

Em 2008, o governo do Frente Amplio, promulgou a lei 18.384 de criação das Cooperativas de Trabalho Artístico no Uruguai o que deu lugar a criação de Valorarte, uma cooperativa de trabalho que reúne a artistas de teatro e dança. Desde uma abordagem qualitativa de caráter exploratório, o objetivo desde trabalho é examinar as características das reivindicações coletivas e defesa de interesses comuns em torno ao trabalho nesta cooperativa. Partindo de entrevistas, se analisam as problemáticas laborais artísticas em uma dimensão contraditória: como possíveis conflitos anticapitalistas ligados as lutas contra o trabalho características das vanguardas artísticas do século XX que hoje se reatualizam na possibilidade do trabalho autônomo como liberação do trabalho; ou a equiparação da produção cultural como qualquer tipo de produção possível de ser regulada como o paradigma de trabalho assalariado clássico no marco do modelo pós fordista atual. Se apresenta uma sínteses das concepções sobre o trabalho e a organização coletiva dos integrantes da cooperativa discutindo a ambigüidade entre liberação e regulação do trabalho artístico e as consequiências da ação coletiva sustentadas sobre uma ou outra concepção.

Palavras-chave: autonomia; cooperativas; trabalho cultural.

\section{Introducción}

En el actual panorama social latinoamericano de descenso de las clases medias y la nueva generación de trabajo autónomo (BOLOGNA, 2006), el cambio en la estructura ocupacional y la sumisión de la actividad creadora (BERARDI, 2012), los trabajadores escénicos se enfrentan a paradojas y dificultades en el reconocimiento de su actividad, en la regulación de sus condiciones de trabajo (y producción de obra) y en el pleno desenvolvimiento de su práctica. Son considerados "trabajadores especiales por las condiciones sui generis en las que desempeñan su labor, la especialización propia de su actividad y la constante desatención sobre sus condiciones laborales" (FEREGRINO, 2011, p.95). Diversas legislaciones en el mundo han sido modificadas con la intención de incluir a este grupo laboral y soslayar la precariedad laboral en la que viven.

La Recomendación del año 1980 de la UNESCO relativa a la condición del artista en donde insta a los Estados miembros a mejorar la situación profesional, social, económica de los artistas mediante la aplicación de políticas diversas es prueba de una larga trayectoria en la búsqueda de respuestas para una mejora de la labor artística ${ }^{3}$. La pionera experiencia francesa conocida como los intermitentes del espectáculo es un antecedente importante en la capacidad

\footnotetext{
${ }^{3}$ La Recomendación fue adoptada por la Conferencia General de la UNESCO en su 21. a reunión de 1980. Disponible en: https://es.unesco.org/creativity/governance/1980-recommendation Consultado 3/4/20.
} 
de articulación de demandas colectivas de trabajadores y trabajadoras del espectáculo (CORSANI, 2006). Así como las largas experiencias de organización sindical en el ámbito artístico a nivel regional, como la Asociación Argentina de Actores que se funda en 1919, en Chile el sindicato de actores en 1967 en Uruguay, la Sociedad Uruguaya de Actores nace en el año 1941 y la Federación Uruguaya de Músicos en el año 1953. Hoy en día las experiencias de cooperativas de facturación o de impulso empresarial que nuclean a artistas, son un nuevo modelo que busca dar respuesta a la situación de vulnerabilidad laboral del trabajo autónomo con funcionamiento en varios países (HERNÁNDEZ, 2017).

Las artes escénicas en especial, esta situación es extensible a las prácticas artísticas en general, tienen un lugar por lo menos ambiguo, difuso, contradictorio, con relación al mundo del trabajo y la producción capitalista en su sentido más tradicional de la fábrica, la producción en serie, el trabajo asalariado y el obrero. Existe cierto imaginario que coloca "al arte como esfera diferencial y autónoma, dedicada a la búsqueda de valores particulares "belleza", "autenticidad", "verdad" - que sería la antítesis de los valores asumidos en el mundo de la economía - la búsqueda racional de ganancia o el ilimitado instrumentalismo" (DU GAY, 1997; WACQUANT, 2005 en INFANTINO, 2011, p. 142). Las prácticas artísticas conjugan una suerte de valoraciones opuesta en relación con el trabajo, "por momentos negativas en tanto pérdida de tiempo valioso y productivo; por momentos positivas como espacio de creatividad, liberación, emancipación” (INFANTINO, 2011, p. 145).

Frente a las contradicciones que se suscitan en torno al quehacer artístico han sido extensos los debates de disciplinas tan variadas como la teoría del arte, la sociología, la economía cultura la filosofía en torno a la función social del arte y su cercanía o distancia con una posición crítica, así como su dimensión ideológica y de clase. Algunas de las discusiones entre los años '70 y '80 referían al problema de la autonomía, el carácter institucional del arte, la relación con los procesos sociales y el debate sobre arte puro versus arte comprometido (MOLANO, 2012). Así como también el vínculo de las prácticas artísticas con el goce que estas desencadenan y permiten como experiencia estética primordial (JAUSS, 2002). Lo que dará paso al replanteamiento de la pregunta sobre el lugar del quehacer artístico y la experiencia estética en las sociedades actuales, en donde el arte es reformulado para ser entendido como una forma de conocimiento y comunicación, así como una ruptura radical de las estructuras sociales (incluido el trabajo), "el antagonismo compromiso/autonomía se reformula entonces en términos de una suerte de integrismo del arte a la vida cotidiana y una suerte de mirada del arte como shock o trauma" (MOLANO, 2012, p. 80). 
Más allá de preguntarnos por el compromiso de las artes en lo social de manera general y sus posibles dimensiones, lo que busca esta investigación es explorar la capacidad crítica del quehacer escénico en tanto sujeto de cambio organizado en torno al trabajo, en este caso, en Cooperativas de Trabajo Artístico en el marco del cooperativismo uruguayo. En particular poner el foco en los proyectos de defensa de intereses colectivos que surgen cuando se asume el quehacer escénico como una fuente de ingresos que permita sostener la vida. Y de los cual se esperan derechos sociales asociados a la condición del arte como trabajo y el artista como trabajador en tanto sujeto político. Pero sin dejar de lado, el nexo insoslayable con la ambigüedad, con la contradicción, de las manifestaciones que asumen que el quehacer escénico también tiene en su especificidad cierta distancia constitutiva con las características del trabajo asalariado y las formas de producción capitalista, más allá de vivir del trabajo escénico o pretender que sea la principal fuente de sustento.

De este modo, el trabajo se entiende en su doble verdad, como actividad y como relación social, "como principio abstracto de estructuración de las relaciones sociales", es decir, "como un trabajo que no va a poder ser recluido en los límites de una fábrica o de un laboratorio, ni simplemente adscrito a quienes dentro de esos límites desarrollan algún tipo de actividad” (GARCÍA LÓPEZ, LAGO BLASCO, MESEGUER, RIESCO, 2005, p.13-14).

En el modelo de acumulación actual, en donde las artes fungen como modelo para las relaciones de producción contemporáneas (VIRNO, 2003), el quehacer artístico es de los ámbitos más afectados por los procesos de transformación laboral que se vienen dando a nivel global, tales como la creciente flexibilización del trabajo, la precarización de las condiciones laborales, la monopolización de servicios y contenidos culturales y la necesidad de asumir los costos y los riesgos por parte de los propios trabajadores. Aunado a las dificultades que las políticas culturales tienen para atender las condiciones laborales y dar respuesta a la invisibilización y desatención del quehacer artístico en sus particularidades; situación agravada y que cobró mayor visibilidad en el marco del COVID-19, cuando la actividad teatral y de formación escénica quedó suspendida, dejando sin ingresos y fuentes laborales a muchas personas.

En este marco de reconfiguración de los modos de producción cultural se investigó la formación de Cooperativas de Trabajo Artístico en Uruguay tras la promulgación de la Ley 18.384 (Estatuto del Artista y Oficios Conexos) como respuesta colectiva a las dificultades laborales de los trabajadores escénicos. Específicamente Valorarte, cooperativa creada en este marco por la Sociedad Uruguaya de Actores (SUA) junto a la Asociación de Danza del Uruguay 
(ADDU), que tiene como centro el trabajo asalariado como paradigma y las mejoras en sus condiciones laborales como eje de sus reivindicaciones y organización colectiva.

A continuación, se presentará una síntesis de la metodología utilizadas, las perspectivas teóricas del presente trabajo: la posición de lo artístico contra el trabajo, la reivindicación de luchas colectivas que lo asumen como trabajo y el cruce de las ambigüedades a las que se enfrentan las cooperativas de trabajo artístico en la actual coyuntura de capitalismo cultural en el modelo posfordista de reorganización del trabajo. (BREA, 2009). Por último, se mostrarán sintéticamente algunos hallazgos en torno a las nociones de trabajo y reivindicaciones colectivas que están atravesadas por percepciones disímiles en la experiencia de Valorarte. La pregunta de fondo que guía la investigación, de la cual este trabajo es un planteo inicial, indaga sobre la posibilidad de la transformación política que le es inherente a la organización del trabajo escénico.

\section{Metodología}

El presente estudio tiene un enfoque de investigación cualitativo de carácter exploratorio que buscó acercarse al fenómeno de las Cooperativas de Trabajo Artístico surgidas en Uruguay en el año 2008 en marco del Sistema Cooperativo (Ley 18.407). La investigación se acotó a Valorarte, cooperativa que nuclea al teatro y la danza conformada por la Sociedad Uruguaya de Actores (SUA) junto a la Asociación de Danza del Uruguay (ADDU) con unos 1500 socios aproximadamente. El objetivo fue examinar los modos en que los trabajadores escénicos que la integran conciben el trabajo, las reivindicaciones colectivas y la defensa de intereses en la conformación de instituciones colectivas determinadas por una práctica común en el marco del cooperativismo uruguayo.

La elección de las artes escénicas en su modalidad de teatro y danza responde a la peculiaridad de que, para que ocurran, tiene que haber un público, lo que las vuelve menos asimilables linealmente a las lógicas de las industrias culturales de reproductividad y momentaneidad, y por ende, presentan una mayor dificultad en la regulación de su trabajo.

Se realizaron un total de 22 entrevistas semiestructuradas a integrantes de la cooperativa Valorarte con diversas trayectorias laborales y experiencias a la interna de la organización. Como primer acercamiento se hicieron inicialmente entrevistas preparatorias en la Escuela Multidisciplinaria de Arte Dramático (EMAD) dependiente de la Intendencia de Montevideo (IM), a ocho personas vinculadas al ámbito teatral de diferentes edades y 
experiencias, miembros de Valorarte y no miembros. La pauta de entrevista se organizó en cuatro ejes temáticos, además de la caracterización de la actual situación laboral y de la trayectoria laboral. Las entrevistas se realizaron por muestreo teórico y respondió a la identificación inicial de los conceptos clave: reivindicaciones laborales y la práctica artística alejada de la noción de trabajo.

Se realizaron entrevistas a hombres y mujeres integrantes de Valorarte incluyendo casos que: 1) formen o hayan formado parte de la comisión directiva de la cooperativa, 2) que no hayan sido parte de la comisión directiva, 3) se seleccionó una muestra por cadena, para los casos que no formaron parte de la comisión directiva de Valorarte que incluyera: cierta participación en la cooperativa o el sindicato y casos con escasa o nula participación. La distribución por género coincidió con las características del sector con una mayor representatividad de las mujeres ${ }^{4}$. Respecto a las edades de las personas entrevistada estás son heterogéneas, entre los 23 y 65 años. Se entrevistó también a dos personas del ámbito cooperativista integrantes del Instituto Nacional del Cooperativismo (INACOOP) y de la Confederación Uruguaya de Entidades Cooperativas (CUDECOOP) y a tres personas integrantes del Sindicato Único de Actores, de la Asociación de Danza del Uruguay y de de la Cooperativa de las Artes del Uruguay (COOPARTE). Las entrevistas se realizaron entre marzo de 2019 y julio de 2020.

\section{Entre las luchas contra el trabajo y por el trabajo}

El capital no domina la producción artística como domina la producción en la tradicional fábrica fordista que se encuentra determinada por la existencia misma del capital. (DURÁN, 2014). Para López Cuenca (2016, p. 17), el trabajo productivo en el capitalismo es el trabajo asalariado utilizado para la producción de mercancía y el reforzamiento del sistema hegemónico de producción. Las prácticas artísticas son:

en términos generales, trabajo no asalariado, siendo algunas prácticas artísticas improductivas para el capitalismo y su lógica de mercado. No quiere decir que no produzcan nada: producen subjetividad, agencia o relaciones sociales, pero, en principio, no generan capital (LÓPEZ CUENCA, 2016, p.17).

\footnotetext{
${ }^{4}$ Para un mayor desarrollo de las relaciones de género en las artes escénicas ver DOMINZAIN, S, CASTELLI, L, DUARTE, D, IBARGOYEN, I (2020) Desigualdades de género en las políticas culturales. Un debate pendiente. Intendencia de Montevideo, Facultad de Humanidades y Ciencias de la Educación.
} 
El trabajo tiene para la economía clásica connotaciones positivas, como dignificante y fruto de la riqueza. Y es considerado por buena parte del pensamiento marxista como condición necesaria para la realización de la vida y motor de la historia (BAUDRILLARD, 2000). Pero la idea de trabajar productivamente la mayor parte del día y la centralidad del salario es algo que no sucedió hasta finales del siglo XVIII y que aún no sucede en muchas sociedades hasta el día de hoy. La división del trabajo como condicionante de la creación de valor económico y organización social proviene de un tiempo relativamente corto, en la Revolución Industrial (MILLER, 2018).

El trabajo productivo en el capitalismo es una obligación, las prácticas artísticas, inclusive con la integración cada vez mayor del arte y del artista al mercado, fungen en esta ambigüedad que le es inherente, como ámbitos posibles de improductividad, de ocio. No como inmovilidad, quietud, sino como rechazo al trabajo, como una toma de posición en relación con las condiciones de existencia impuestas por el capitalismo (LAZZARATO, 2015). Perspectiva que ha caracterizado a las vanguardias artísticas desde el siglo XX contra la subordinación de la vida al capital. Para Mauricio Lazzarato, es Duchamp uno de los exponentes más radicales del arte del siglo $\mathrm{XX}$ del principio ético político del rechazo al trabajo, objetando función, norma y productividad de la sociedad capitalista. Esta posibilidad de la no producción en su sentido tradicional, este parcial distanciamiento con la productividad capitalista evoca las tradiciones de pensamiento occidental de los siglos XIX y $\mathrm{XX}$ en contra del trabajo asalariado, la normalización, la reificación y el tiempo de la producción, de la que las prácticas artísticas beben (LAZZARATO, 2015). En el "no hacer nada" de las luchas contra el trabajo, en el des-obrar radical que interrumpe la producción y las jerarquías del trabajo, radica una de las formas de crítica del quehacer artístico y su gesto emancipador (LAZZARATO, 2015).

En una sociedad basada en la oposición entre trabajar y disfrutar, el gesto del goce y el disfrute que la actividad artística tiene como condición para su generación, es otra manera de confrontar las ideas clásicas que ligan al trabajo con el sufrimiento, el martirio y la seriedad. Para Brecht, la categoría histórico social del placer y la diversión en el arte son centrales, el placer no proviene solo de la contemplación sino del proceso creador mismo y de la posibilidad de producir una nueva realidad humana, de autoproducirse. El teatro sirve para hacer más llevadera la existencia y ayudar a explicar el mundo y a transformarlo, es decir, colabora en la producción de relaciones sociales y en la autocreación del ser humano. Ya Marx había asociado el concepto de placer con el de creación o trabajo creativo y su opuesto, 
trabajo alienado, e hizo explícito el problema de la creación artística ya que consideraba que la producción capitalista destruye el principio creador de la actividad práctica humana (SÁNCHEZ VÁZQUEZ, 1975).

En el análisis marxiano hay varias concepciones utópicas del trabajo que los diversos movimientos políticos y culturales del ' 68 en el mundo retoman "en su convergencia cultural y productiva con el movimiento de rechazo al trabajo industrial" (BERARDI, 2012, p. 22). La dualidad y doble condición de la producción artística y la resistencia que estaría ligada a su misma particularidad como producción, son extensibles a la crítica marxista al trabajo en el capitalismo. En la medida en que es central la noción de la naturaleza bifacética del trabajo, el doble carácter del trabajo, según sea expresado en valor de uso o valor de cambio, es decir en un hacer alienado, pero simultáneamente, en la potencia de un hacer no alienado (HOLLOWAY, 2011). El pensamiento obrerista de la década de los '60 va a reactualizar esta crítica marxista, entendiendo que es esta fisura, este desborde de lo meramente productivo que anida en la producción artística, este rechazo al trabajo es una característica del trabajo cognitivo contemporáneo, que, en su inconmensurabilidad, en su autonomía, podría constituirse por fuera de las relaciones propiamente capitalistas (NEGRI, 1999).

Ahora bien, como todo fenómeno social, las prácticas escénicas intervienen en la vida social y política, se insertan en un proceso histórico (REMEDI, 2017). Ningún trabajo, inclusive el trabajo artístico, es ajeno a las relaciones de poder que trastocan sus contenidos y "por ende la situación del artista en una historicidad no es ajena a la organización en su contexto de la esfera del trabajo" (BREA, 2009, p.4). Durán (2012) señala la imposibilidad de las determinaciones generales del artista a las relaciones generales de cambio, la venta de fuerza de trabajo en forma de mercancía y la lucha de clases. El artista no es ajeno a los condicionamientos sociales y el desarrollo específico de la producción de arte en la sociedad capitalista, ya que, "el producto ofrecido por la fuerza de trabajo artística es un producto cuya determinación es la forma mercancía" (DURAN, 2012, p.207).

Las industrias culturales han añadido una mayor complejidad a la ambigua situación del artista como trabajador. Al regularizarse y monopolizarse la producción cultural a escala global, se organiza el trabajo en lo que Miller (2018) llama la Nueva División Internacional del Trabajo Cultural, en donde a medida que el capitalismo se extiende mundialmente y se especializa, oculta el trabajo que lo constituye. En la distancia con el trabajo asalariado como relación social —y por ende, de la figura del trabajador — se solapan las condiciones laborales precarias y de explotación que los trabajadores culturales han tenido históricamente. Con la 
necesaria complejización de la noción de precarización, no solo como algo impuesto, sino también posible de ser elegida para sí, en lo que contribuye a generar las condiciones que permiten ser parte activa de las relaciones políticas y económicas neoliberales, a partir de la noción de la libre elección de tener una vida precaria y autónoma (LOREY, 2008).

A la par que la misma excepcionalidad que pretende proteger la producción cultural y el quehacer artístico de las lógicas instrumentales del mercado y de Estado, enmascaran condiciones laborales y de explotación de los trabajadores artísticos. La figura que surge de la mano de las industrias culturales es la del empresario, el emprendedor cultural, que reemplaza al artista o al artista trabajador. Paradójicamente nace lo que Rowan denomina el sujetoempresa, el empresario de sí mismo, "que compite en el mercado por mantener su nicho y hacerse visible en el mercado bajo las lógicas de las marcas" (ROWAN, 2016, p.30), alejado de la tradicional concepción del trabajador asalariado, del movimiento social de los colectivos artísticos y la crítica social.

El vínculo histórico entre compromiso social y lucha de clases parece romperse con las nuevas configuraciones posfordistas de la centralidad del trabajo cognitivo y el ascenso de la clase creativa en el hecho de ser, al mismo tiempo, trabajo y capital (BOLOGNA, 2006). La utopía del trabajo y del trabajo artístico en particular, en tanto expresión, juego, libertad no normalizada y posible nueva subjetividad se torna difícil en la sociedad de la mercancía y el mercado posfordista. Lazzarato (2015, p.16) lo va a expresar como la ambigüedad imposible: ¿emancipación del trabajo o emancipación por el trabajo?

En relación con las transformaciones del trabajo, las luchas por el trabajo y las perspectivas de liberación de los movimientos obreros, el papel del artista está embebido de la misma ambigüedad que tiene el arte frente al trabajo: entre ser artista o trabajador, entre crítica social o crítica artística, entre mercancía o no mercancía, entre autonomía o capital. La crítica social del quehacer escénico podría estar, por un lado, en la natural ambigüedad constitutiva de autonomía relativa respecto a la producción capitalista. Y por otro, en su condición de trabajo organizado contra el capital. Dimensiones de lo político muchas veces contrapuestas o contradictorias que provocan diversas maneras de entender las reivindicaciones en torno al trabajo artístico y sus acciones.

Como militante, el artista debe sumarse a la causa de "otros". El vínculo abierto por el '68 entre movimiento obrero y estudiantil profundizó la alianza entre trabajo intelectual y lucha obrera dejando de lado las propias condiciones de vida de los artistas como espacio de 
conflicto directo o sin una mayor problematización sobre las propias condiciones de producción.

El artista como militante debe colaborar con la emancipación de sectores "supuestamente sometidos por esas relaciones de clase, lo cual crea claramente una división entre un "nosotros" (supuestamente) emancipado y un "ellos" sometido (MAURO, 2018, p.210).

A su vez, como trabajador, el artista debe defender sus propias condiciones de existencia, considerase como cualquier otro trabajador cercano a algún tipo de explotación, formalizar su trabajo y limitar las condiciones de producción a marcos normativos que podrían estar más cerca al "trabajo alienado" que al trabajo creativo y que tiene como destino el Estado o el mercado. Pero con la salvedad de no contar con las formas del conflicto históricamente determinadas del trabajo asalariado, como la huelga u otro tipo de acción colectiva (BOLOGNA, 2006) ${ }^{5}$.

Para la Teoría Crítica de la Escuela de Frankfurt —especialmente en los desarrollos teóricos de Theodor Adorno y Walter Benjamin- los trabajadores cerebrales, como los definía Bertolt Brecht, estaban más cerca al proletariado que a los capitalistas y su función no era la de liderar, sino la de experimentar, "permanentemente desafiando el dogma" (BUCKMORSS, 2011, p.96). Es su condición de "artistas" lo que les da la posibilidad crítica y no la de "trabajadores", aunque su estatuto sea estar más cerca del proletariado que de la burguesía. Lo que contaba no era el origen burgués de las técnicas, en este caso artística, sino la actitud crítica que el intelectual le aportaba. Para Adorno, "el arte válido revelaba las contradicciones sociales antes de presentar su resolución estética" (BUCK-MORSS, 2011, p.97-98).

La dificultad de los artistas para configurarse como trabajadores está atravesado de estas múltiples ambigüedades históricamente determinadas que hacen a la práctica escénica. Pero también, aquí solo dejaremos apenas esgrimido el argumento, hay en esa ambigüedad una dimensión que creemos importante destacar. Y que es lo que llamamos luchas contra el trabajo tal cual lo conocemos, sus reglas, obligaciones y sentido social. Imaginar un no trabajo en un sentido disruptivo, que permite la posibilidad de una reorganización crítica del trabajo más allá de las instituciones conocidas, nos permite sustraernos —aunque sea

\footnotetext{
${ }^{5}$ Con esto no estamos diciendo que no haya experiencias de huelga de los trabajadores del espectáculo. Así lo demuestra el caso argentino de huelga de actores a principios del siglo XX (1919-1921) en un contexto de conflictividad internacional en torno al trabajo (MAURO, 2018). Y más recientemente en el 2004, la Coordinadora de Intermitentes y precarios del espectáculo en Francia aparece como una excepción cuando reivindican que no hay cultura sin derechos (LAZZARATO, 2006). A los que hacemos referencia es a la noción actual de trabajo autónomo en la que se incluye al trabajo cultural y que no tiene la capacidad del conflicto en su sentido tradicional de protesta colectiva y huelga general (BOLOGNA, 2006, p.142).
} 
momentáneamente y con muchas dificultades dados los complejos mecanismos de explotación - a la relación capital trabajo, y a las formas tradicionales de organización laboral sindical.

En este giro regulador actual, donde la función de la precarización, de contradicción al interior del dispositivo capitalista, pasa a función de normalización, Lorey (2008) llama la atención sobre la precarización como un proceso que no solo produce sujetos, sino también inseguridad, en tanto preocupación central del sujeto y que nos prepara para la necesidad de seguridad como ideal político, un ideal que sirve para acumular poder dentro del Estado y de las instituciones (BUTLER n LOREY, 2016). De ahí se deriva la pregunta fundamental, activadora, sobre cómo las dinámicas de subjetivación pueden ser punto de partida para las luchas políticas, en tanto espacio de posibilidad — por sobre el miedo y en un vínculo distinto consigo mismo y los demás - en la ambivalencia entre sujeción y libertad que les son inherentes (LOREY, 2016).

El intento de igualación del trabajo escénico a cualquier otro trabajo, posible de ser regulado e incluido en relaciones salariales, al mismo tiempo que busca afirmar derechos laborales e identidades colectivas alrededor del trabajo, pretende también enmarcar, solidificar, integrar a las lógicas del mercado, sacar ganancia, de una actividad que, en principio, no es tan cuantificable ni reducible a las formas tradicionales del valor. No es esperable, ni deseable, que las prácticas escénicas, como una forma de la producción de sentidos compartida capaz de elaborar discursos complejos y estéticas significativas no excluyentes (ROWAN, 2016) sean sometidas íntegramente a las lógicas de la industria cultural y el capital.

Los análisis que solo pueden mirar desde la perspectiva del trabajo verán en las formas de producción y organización del hacer, una falacia, una carencia, una ausencia de seguridad y de derechos que garantiza el ser sujetos trabajadores. Pero si miramos la posibilidad de un hacer que no es un trabajo, porque no busca serlo, pero que no por ello deja de reconocer la necesidad de encontrar mecanismos de financiamiento y retribución económica, es justo ahí, en este contradictorio límite, donde se puede buscar e identificar derechos ya consagrados adaptados a las nuevas modalidades de explotación del tiempo presente. 


\section{Capitalismo cognitivo y trabajo autónomo}

La desaparición del fordismo y la aparición de un capitalismo global neoliberal desde finales de la década de los '80 ha impactado en el mundo occidental generado profundas transformaciones sobre el trabajo y las relaciones laborales, que aportan renovadas formas de dominación y explotación a nivel mundial. Se incorpora como novedad al conocimiento, el trabajo inmaterial, la producción cultural, la información y la creatividad como ampliadas formas de generación de valor, que conviven con las formas más tradicionales del capital, el trabajo y la tierra. El problema del arte como trabajo en su contradictoria condición de mercancía y no mercancía, de productividad e improductividad, toma relevancia.

Varios autores vienen señalando las nuevas dinámicas de acumulación y explotación que son posibles gracias a una rearticulación, relocalización, de la producción cultural y simbólica en los mecanismos de dominio económico globalizantes. A esta nueva fase del desarrollo capitalista se le ha denominado capitalismo cognitivo (MOULIER BOUNTAN, 2004), sociedad de la información (CASTELLS, 1996), sociedad pos-fordista (LAZZARATO, 2008) o capitalismo cultural (BREA, 2009). Conceptualizaciones que denotan el carácter digital de la producción, que involucra, de modo preponderante, mente, relación y lenguaje (BERARDI, 2012). Es la capacidad semiótica del arte, su poder para producir y hacer circular signo, lo que lo haría especialmente valioso para la lógica del capitalismo cognitivo (LÓPEZ CUENCA, 2016). Lo que da lugar a nuevos vínculos y zonas de articulación entre la esfera económica, la producción cultural y los movimientos artísticos.

La entrada del capitalismo contemporáneo en esta nueva fase tiene lugar, para Brea, al generarse una colisión sistémica entre "el sistema económico-productivo y el subsistema de las prácticas culturales y de representación" (BREA, 2009, p.12). La separación histórica entre trabajo intelectual y trabajo manual se desdibuja, y surge un nuevo modo de trabajo. El análisis que hace Brea, les da a las prácticas culturales, la función de cumplir con las demandas de expectativas de sentido y emoción fundamentales de la ciudadanía y la acumulación capitalista.

La separación simbólica que constituía al artista en una casta separada se desvanece, y la colisión de economía y cultura, por un lado, y de trabajo material e inmaterial, por otro, determina un desplazamiento estructural del "trabajo artista" desde su distante "torre de marfil" a un nuevo escenario plenamente integrado en el marco de ésas que hemos descrito como industrias de la subjetividad (BREA, 2009, p.15).

La producción cultural tiene hoy una nueva concepción, expandida, ampliada, que se encuadra en la ecuación cultura-desarrollo que se promueve en Latinoamérica tras el consenso 
de Washington en 1987 y que genera cambios en el estatuto de la cultura como espacio privilegiado para la producción de hegemonía (ROWAN, 2016). Se introduce explícitamente el carácter económico de las prácticas artísticas y culturales y el fortalecimiento de los derechos de propiedad intelectual lo que va a colocar las luchas y disputas del trabajo no solo en el campo material, si no también, en el campo simbólico ${ }^{6}$.

El estatuto de trabajador asalariado que ha representado la forma general de la ciudadanía - por lo menos en los países Occidentales-, entra en colapso con el debilitamiento de los llamados Estados de Bienestar. La nueva forma de organización capitalista posfordista requiere una sociedad de trabajadores por cuenta propia, no asalariados, una nueva generación de trabajo autónomo (BOLOGNA, 2006).

Para Bologna, lo que lo caracteriza este trabajo autónomo posfordista no es la forma de contrato, sino "su naturaleza jurídica nueva, más cercana a la relación comercial entre dos entidades en igual relación de fuerza, que, a una relación de dependencia” (BOLOGNA, 2006, p.149), la relación es concebida como una relación comercial de dos entidades empresas similares. Sin protección social ni salario, recibe una retribución que debe bastar para su reproducción y una compensación por la prestación de un servicio que, por lo general, es pagado meses después de realizado el trabajo. Más cercano a una relación comercial que una relación entre trabajador y empleador. Características que pueden ser extensibles a la mayoría del trabajo escénico, distinguiendo entre trabajo autónomo de tipo tradicional, típico de la agricultura, el comercio y las profesiones liberales protegidas por colegios (abogados, arquitectos, médicos, etc.) del trabajo autónomo de segunda generación.

Cuyos efectos son muy inferiores, pero que está experimentando un rápido crecimiento provocado por el incremento de los "profesionales del trabajo cognitivo" (como la industria de los medios de comunicación de masas y el ocio) y de los dedicados al servicio a las personas (BOLOGNA, 2006, p.74).

El proceso de sustitución de un modelo de producción por otro no es claro, ni lineal ni completo en términos de la efectiva organización del trabajo y la forma de acumulación sobre

\footnotetext{
${ }^{6}$ En Uruguay en línea con estas directrices mundiales se promueven varias políticas culturales e iniciativas como son la creación, en 2007, del Departamento de Industrias Creativas (DICREA), el Sistema de Información Cultural (SIC), la Cuenta Satélite para la Cultura en 2009 y los conglomerados creativos como Audiovisual Uruguay, Conglomerado de Diseño, Conglomerado Editorial y Cluster de Música, que han elaborado información económica relativa a cada uno de estos sectores y desarrollado políticas públicas que entienden lo cultural como un ámbito de desarrollo estatal.
} 
todo en nuestros contextos latinoamericanos. De todos modos, lo que importa destacar es la centralidad que algunos autores dan al trabajo autónomo o al estímulo de relaciones laborales que tienen mayores niveles de cooperación para la conformación de las relaciones capitaltrabajo hoy en día y que es equiparable a las maneras en las que el quehacer escénico se ha organizado desde el siglo XX.

En esta coyuntura de transformaciones del trabajo y nuevas identidades colectivas y con una menor relevancia del trabajo como aglutinante de identidades cobra relevancia cómo se gesta y lleva adelante la defensa de intereses comunes y la protesta de los trabajadores que se desempeñan en condiciones de autonomía formal, pero de sustancial subalternidad, como es el caso de los trabajadores culturales (BOLOGNA, 2006). La producción cultural se vuelve un fenómeno importante para pensar el problema de la representación de intereses ligados al trabajo y al modelo de acumulación actual. El lugar del artista no deja de ser controversial en términos de lucha de clases y desde las miradas más dicotómicas sobre la estructura de clase, la ruptura con la sociedad del salario y la centralidad autonómica como relación capitaltrabajo hoy en día.

\section{Cooperativas de trabajo artístico}

La principal transformación que trae consigo la modernidad capitalista es dejar la fuerza de trabajo artística libre para el mercado que ofrece el producto de su trabajo como mercancía. Cuando se habla de la independencia que el autor moderno ha conquistado gracias al dinero se hace referencia a una independencia con respecto a relaciones sociales anteriores, como el saltimbanqui de la corte y al bufón de antecámara (DURÁN, 2012, p.206). Aunque el trabajo artístico se presente la mayor parte de las veces como trabajo autónomo o atípico, esto no es el resultado de un proceso reciente de flexibilización, como ha ocurrido con otro tipo de trabajos vinculados a servicios, por ejemplo, sino que es una realidad instalada históricamente como parte de las formas de desempeño y desarrollo de la labor ${ }^{7}$.

El sector cultural presenta a escala mundial una importancia creciente en el empleo, "en la producción y el comercio, siendo el empleo del sector cultural entre el 1,5\% y el 3,5\% del total en la mayoría de los países de Europa Occidental y Estados Unidos, manejando cifras similares con respecto a la participación del sector cultura en el PBI" (ASUAGA,

\footnotetext{
${ }^{7} \mathrm{El}$ artista es un trabajador cuando "desarrolla su labor principalmente como medio de vida y no por mero placer estético o acción benéfica, puesto que brinda un servicio cultural integrado a la producción y circulación de bienes y a la actividad comercial y empresarial (COLLAZO, 2004, p.124).
} 
LECUEDER y VIGO, 2005, p.11). La tendencia del sector cultural uruguayo es creciente, representando el 2,9\% del PBI y generando 49.000 empleos (ASUAGA, LECUEDER y VIGO, 2005).

En los últimos años y en especial ante la actual situación sanitaria mundial, salen a la luz viejas situaciones: agudización de la flexibilidad laboral que ha acentuado la desigualdad, la desprotección, la falta de posibilidades laborales, las jerarquías al interior del campo, la flexibilidad como condición "natural", el multiempleo como regla, la ausencia de seguridad social, la dificultad para regular la producción artística y cultural, las desigualdades de género, el trabajo infantil velado como en las publicidades por ejemplo, entre otros fenómenos. Estos han sido opacados, desatendidos y poco se problematizan las condiciones laborales y las maneras como la producción de obra se desenvuelve y genera. Uruguay, con sus particularidades, no es la excepción.

El cooperativismo y el sindicalismo tienen en Uruguay una larga tradición en las luchas por la reorganización del trabajo. La relevancia de los movimientos sindicales es un fenómeno histórico fundamental en el desarrollo del sistema de acumulación y que se aúna al fuerte despliegue del movimiento cooperativista en el intento por mitigar formas de exclusión, desplegando recursos, generando empleos y jugando un papel importante en el desarrollo económico y social. Los orígenes de las cooperativas de trabajo se remontan a fines del siglo XIX y están asociados a trabajadores provenientes del movimiento sindical europeo que traían modelos y propuestas que poco a poco se fueron enraizando en la sociedad uruguaya (MARTI, SORIA y DABEZIES, 2007).

Fruto del contexto de políticas en materia laboral de los tres gobiernos de izquierda, que marcaron un profundo cambio respecto aquellas aplicadas durante la década de 1990 e inicios del siglo XXI, es que se reconoce por primera vez en Uruguay al artista como trabajador, y se regula su actividad con una serie de derechos y obligaciones para formalizar su trabajo, garantizar el acceso a la salud y a la jubilación, a partir de la organización colectiva en cooperativas de trabajo artístico.

La entrada en vigor de la ley 18.384 "Estatuto del Artista y Oficios Conexos" en octubre del 2008 promovida por el Frente Amplio, es impulsada por el Sociedad Uruguaya de Actores (SUA) junto al sindicato de músicos (AUDEM) y de danza (ADDU) esta ley crea un Registro Nacional de Artistas que permite a las personas inscritas formar Cooperativas de Artistas y Oficios Conexos, previstas en la Ley del Sistema Cooperativo (Ley 18.407) en el 
marco de la tradición cooperativista uruguaya. Dentro de esta normativa están incluidos sólo los artistas intérpretes o ejecutantes, entendiendo por tal a todo aquel que represente un papel, cante, recite, declame, interprete o ejecute en cualquier forma una obra artística, la dirija o realice cualquier actividad similar. También están incluidos los técnicos en oficios conexos a estas actividades, como ser: vestuario, maquillaje, escenografía, iluminación, etc. cuyo desarrollo implique un proceso creativo ${ }^{8}$.

Las cooperativas de trabajo artístico tienen como cometido brindar servicios a sus asociados/as, desde la gestión de contratos a la compra conjunta de insumos necesarios, o comercialización de bienes y servicios producidos por los socios y socias, entre otros (ETCHEVERRY, ROMERO y TORRELLI, 2018, p.21). Y tienen de específico que permiten generar aportes intermitentes a la seguridad social, en función de lo realmente percibido, cobrando una comisión por dicho trabajo administrativo ${ }^{9}$. A diez años de la implementación de la ley son cinco las cooperativas conformadas (Valorarte, Coopaudem, Cooparte, Murga Agarrate Catalina y Teatro para el fin del mundo). Se identifican dos grandes modelos de cooperativas de artistas, relacionados en buena medida con su matriz de surgimiento: las paraguas de más de 2000 socios de origen sindical, que funcionan similar a las cooperativas de socios, entendidas como una herramienta sindical, como es el caso estudiado de Valorarte; y las cooperativas más chicas, de 50 socios o menos, que se asocian con una práctica autogestiva y se parece más a una cooperativa de trabajo clásica (ETCHEVERRY, ROMERO y TORRELLI, 2018).

Valorarte fue fundada en 2009 y comienza a funcionar en 2011, integrada por socios/as de la Sociedad Uruguaya de Actores y Asociación de Danza del Uruguay. Se compone de aproximadamente 1500 cooperativistas, cifra estimada ya que no llevan un control estricto de sus asociados y muchos de ellos tiene una actividad muy esporádica. $\mathrm{Su}$ sede está en Montevideo, aunque sus socios y socias son de todo el país. Comparte sede, funcionarios y recursos con SUA y hay un fuerte vínculo entre ambos, tanto que a veces las mismas personas integran ambas directivas, además de que es requisito de ingreso a la cooperativa ser socio del sindicato y pagar una cuota mensual. Valorarte sirve de amparo al trabajador autónomo que no puede hacerse cargo de los costos fijos de una empresa Unipersonal-Servicios Personales fuera de la relación de dependencia, función que SUA ya

\footnotetext{
${ }^{8}$ Disponible en: http://www.bps.gub.uy/5037/sistema-de-seguridad-social-para-artistas-y-oficios-vinculados-alarte.html

9 Ley N. ${ }^{\circ} 18.407$ (2008) IMPO. Ley del Sistema Cooperativo. Disponible en: https://www.impo.com.uy/bases/leyes/18407-2008
} 
cumplía antes de la promulgación de la ley, pero sin la posibilidad de que el trabajador generara aportes ni seguridad social.

Ofrece como característica determinante de esta matriz de surgimiento, la administración del trabajo del socio, al ocuparse de la emisión de la factura a los contratantes, de seguimiento, cobre, liquidación de haberes y tributos correspondientes al Banco de Previsión Social y a la Dirección General impositiva y pago al socio. Esta modalidad de funcionamiento la asemeja a una cooperativa de facturación o de impulso empresarial, nuevo modelo cooperativo que nace desde la economía social para dar cobertura al trabajador autónomo (HERNÁNDEZ, 2017) ${ }^{10}$.

El modelo de economía social se está utilizando, en algunos casos, de forma aparente cuando de lo que, en realidad, se trata es de una plataforma de intermediación y de prestación de determinados servicios al profesional autónomo para que éste pueda desarrollar su actividad no siendo su posición frente a la entidad la de un socio cooperativista, sino la de mero cliente de la entidad (HERNANDEZ, 2017, p.180).

Su principal función es la gestión de contratos sobre todo para el Estado, a través de los fondos públicos destinados al fomento de la actividad artística de la Intendencia de Montevideo, el Ministerio de Educación y Cultura y el Ministerio de Desarrollo Social y, en lo privado, principalmente cine y publicidad. Etcheverry et., al (2018, p.14) mencionan que, para Valorarte, la reciente ley de cine cambió el panorama de contratos/ingresos, donde un $48 \%$ proviene del ámbito público y un $48 \%$ del privado.

Algunos cuestionamientos a este modelo cooperativo tienen que ver con facilitarle al Estado la gestión de altas y bajas de la seguridad social característica del trabajo escénico intermitente, que pasan a estar en manos de la cooperativa y la justificación contable de los gastos, así como el ahorro por parte del Estado del pago de aportes patronales que corren por cuenta del trabajador. Valorarte se financia exclusivamente con un porcentaje del contrato de los asociados que es un 5\%, salvo los contratos con la Intendencia de Montevideo que es el único ente público que se hace cargo de ese 5\%, "que paga como comisión por la administración de una gestión tercerizada y la misma incluye los aportes personales en el caché del artista, de forma de no reducir los ingresos de este" (ETCHEVERRY, et., al, 2018, p.15).

En Uruguay, la tradición de autogestión en el arte es amplia y profunda, pero su operacionalización formal bajo formato cooperativo es muy escasa (ETCHEVERRY, et., al,

\footnotetext{
${ }^{10}$ Algunos ejemplos en el mundo son la Societé Muetuelle pour artista, Coopart, Músicos Unidos, Cooperativa de Trabalho dos Profissionais de Música de São Paulo, entre otras.
} 
2018). Las cooperativas de trabajo artístico no suplantan la forma de organización del trabajo tradicional del teatro independiente uruguayo autogestivo-cooperativo-militante, que tiene sus raíces en las experiencias en común en ambas orillas del Río de la Plata. Y que, a diferencia del caso argentino, no tiene reglamentación formal y ha tenido poca incidencia en problemáticas laborales específicas donde la "apelación a la militancia funcionó como un factor retardatario en la conciencia laboral de los artistas", dejando la confrontación y regulación del trabajo a los sindicatos (MAURO, 2015, p.11).

Valorarte aparece con una identidad peculiar, de búsqueda de respeto de las cláusulas contractuales y herramientas de negociación dentro del paradigma de lucha del trabajo asalariado, a partir de una nueva forma cooperativa más cercana a una cooperativa de socios que de trabajo, que busca dar respuesta a las necesidades del trabajo no asalariado autónomo intentando conciliar "iniciativas individuales con un enfoque colectivo, cooperativo y mutualista" (HERNÁNDEZ, 2017, p.168). Es importante comprender el rol de las cooperativas, no como organizaciones aisladas, sino como espacios de lo político, que afectan a otros sectores productivos en un contexto de flexibilización laboral y de radicalización de los procesos de individualización.

\section{El abismo de la autonomía}

Abordaremos sintéticamente algunos de los aspectos que nos parecen más relevantes en torno a las percepciones sobre la defensa de intereses colectivos y sobre las nociones de trabajo que los integrantes de la cooperativa de trabajo artístico Valorarte tienen en su experiencia de organización.

El vínculo entre Valorarte y SUA es muy estrecho, tanto que a veces se llega a confundir la identidad de ambas organizaciones, con una relevancia del sindicato por sobre la cooperativa, dada la larga trayectoria de organización que tiene la agrupación gremial fundada en 1941 y la coyuntura de formación de la cooperativa. Si observamos en la página web de la sociedad de actores se la nombra como "la Cooperativa de SUA"11 y es definida por los propios miembros de Valorarte como una herramienta sindical. La gestión del trabajo pasa por la cooperativa, las negociaciones sindicales por SUA. Este solapamiento entre las dos instancias organizativas - cooperativa y sindicato - condiciona la identidad de la cooperativa y las percepciones sobre su función y alcance, acercándose a los modelos cooperativos de 11 Información extraída de la página web de la Sociedad Uruguaya de Actores. Ver:
http://sua.org.uy/?page_id=2064 
facturación como plataforma de intermediación sin que esto se explicite (HERNÁNDEZ, 2017).

Básicamente la cooperativa, aunque digan que no, es una cooperativa de facturación. La gente que está trabajando está para eso, contratados para eso, funcionarios contratados, son los mismos que SUA y te facturan y te depositan la plata y te avisan. (Mujer, 40 años).

Una de las características a destacar es la distinción entre aquellos que pasaron por la comisión directiva de la cooperativa o tienen participación gremial activa en el sindicato y los socios de la cooperativa, con nula o escasa participación en las instancias colectivas de decisión. Esta diferencia entre los "dirigentes" y los socios "que no participan” es una característica mencionada por todas las personas entrevistadas en relación con la forma de funcionamiento de la cooperativa. Las personas entrevistadas con escasa o nula participación asumen su lugar en la cooperativa asociado a intereses puntuales como la facturación de un trabajo o los contratos con el estado. Y pocas o nulas proyecciones políticas de carácter más general vinculadas con el hecho de integrar la cooperativa o de reivindicaciones más generales para el sector, lo que se asocia a una distancia con la posibilidad de articulación con otros actores o movimientos sociales. Pero sí reconocen al sindicato, no así a la cooperativa, como un interlocutor válido frente al Estado a la hora de negociaciones laborales y pautas de contratación.

En cambio, las personas entrevistadas con larga trayectoria sindical o que participaron de la comisión directiva, perciben la actividad dentro del sindicato o la cooperativa como necesaria y natural dentro del horizonte político de la lucha por el trabajo, asociada a las mejoras en las condiciones laborales y al reclamo de derechos como todos los trabajadores.

Todo lo que trabajo intento que sea formalizado, es como una cuestión que viene de educación familiar, no sé, y mi amor a esto, mi arte, siempre lo encaré como un trabajo, me gusta la forma cooperativa. Esto me da ese margen de participación, sea directo o no, en otro momento no soy directiva y he participado (Mujer, 54 años).

Ante la pregunta por cómo evalúan su rol dentro de la cooperativa, en general es positiva, entienden como sumamente importante la tarea que realizan de dirigencia, ya que permite un vínculo directo con las instancias de negociación con el Estado y actores privados (cine, televisión y publicidad) para regular las condiciones de contratación, cobro y creación de estímulos para el sector. A su vez, valoran la tarea como ardua y compleja en sus diversas instancias de negociación y con una capacidad limitada en términos de fuerzas para lograr las medidas que entienden necesarias para mantener o mejorar las condiciones laborales de los trabajadores escénicos. La fuerza estaría en el supuesto compartido del valor social de la 
creación escénica — puesto en la figura del actor o actriz como su lado más visible - en la legitimidad del conflicto, más que en la capacidad de huelga o la amenaza de la interrupción de la producción como hecho colectivo (BOLOGNA, 2006).

Lo mismo refieren hacia la cooperativa manifestando conformidad por el buen funcionamiento y por su estricta política de cumplimiento de pagos y aportes a la seguridad social a sus asociados, lo que la diferencia de otras cooperativas nacidas bajo la misma ley que son más laxas en la obligación de los aportes sociales.

Otra cuestión de importancia es la falta de participación y vínculo real con la cooperativa y el sindicato de aquellos que no integran la comisión directiva. La falta de participación es una preocupación y es leída por la comisión directiva como un desinterés político y "poca conciencia" sobre la importancia del trabajo. Mientras que los entrevistados que no integran o integraron la comisión argumentan que los mecanismos de participación no les atraen, que es muy burocratizado y que no encuentran un espacio real de reclamo de derechos en la cooperativa, por más que circunstancialmente utilicen su servicio. También vinculan la participación en cargos de dirección a intereses personales y de poder y lógicas sindicales con las que no se sienten a gusto. Esto se manifiesta en las personas entrevistadas en términos de cierta tensión, distancia, "reproche", entre integrantes de la comisión directiva o con una presencia clara en los ámbitos de discusión, con los que no pasaron por esa experiencia de dirección o no están familiarizados con las dinámicas sindicales.

Una cosa es la institucionalidad teatro, que a veces agobia, lo otro es fiesta, disfrute, goce, donde lo que voy a recibir a cambio pasa por otro lado, voy a recibir a cambio el reconocimiento de mis pares (Hombre, 30 años).

Esta escasa participación a la que refieren los entrevistados coincide con la encuesta realizada por Etcheverry et., al. (2018), donde se desprende que un tercio de las y los socios usó la cooperativa en el último año y el vínculo del socio/a con la cooperativa es de usufructo del servicio, más que de participación en la misma.

En general, los entrevistados coinciden en que hay una notoria diferencia que llaman de "ideológica" o de "principios" entre las diversas experiencias en la participación. Esta diferencia de puntos de vista es sustancial para lo que queremos abordar: los que han formado parte de la comisión directiva o participan activamente en el sindicado, creen que el arte escénico es un trabajo "como cualquier otro" posible de ser reivindicado como tal y por lo tanto debe ser regulado, tener cargas sociales y brindar derechos. Los que no han pasado por la comisión directiva tienen nociones menos claras en torno a identificar el arte como un trabajo, de pretender vivir de esta actividad y en algunos casos, creen que no es necesaria su 
regulación para que el quehacer escénico suceda, y en general solventan sus gastos con otras actividades.

Lo que importa es hacer teatro, y a tu manera, la autogestión te lo permite, lo otro no sé o por lo menos no me interesa tanto (Mujer, 23 años).

En este último caso, por más que entienden que la jubilación y la salud son beneficios necesarios en sus vidas, consideran que el monto de los aportes es muy elevado en relación con sus ingresos y que la cooperativa y el sindicato reciben un porcentaje desproporcionado por sus servicios. Y en algunos casos les parece que al ser el trabajador el quién se hace cargo de los aportes sociales, debería ser una posibilidad la elección de decidir hacerlos o no, ya que la obligación de realizar aportes previsionales se interpretaba como una merma en los salarios. A su vez, cierto desinterés o distancia con las lógicas institucionales que regulan el trabajo artístico y que son definidas en términos de "la burocracia" o "la institucionalidad" puede llevar a "experimentar formas de vida no reglamentadas por la disciplina del trabajo", que, como explica Expósito (2008, p.21), en su excepcionalidad se dejen atrapar por los dispositivos de normalización y explotación de las industrias culturales”.

Esta diferencia de perspectivas sobre el trabajo es percibida, por algunas de las personas entrevistadas, también como una diferencia de pensamiento entre generaciones. La actitud de los "más jóvenes" es leída como "parricida" por algunos o "confrontativa", otras personas mencionan un cambio de "mentalidad", de forma de hacer y entender el hecho teatral. Explican que los "más jóvenes" cumplen varios roles a la vez, dirigen, escriben y actúan, rompen con la idea jerárquica del director, montan obras sin depender de salas o de un aparato institucional que los avale o financie.

\footnotetext{
Lo escénico cambió, el sindicato no dialoga mucho con los jóvenes, se han hecho algunos intentos, de comisión de jóvenes, pero al final no funcionó, deje de participar. Y de la cooperativa no se mucho, solo cuando facturo, una vez cada tanto. Eso es culpa de ambas partes (Mujer, 28 años).
}

Ante la pregunta por el vínculo de la cooperativa con las tradiciones del pensamiento de izquierda y con conflictos laborales como conflictos anticapitalistas, las personas entrevistadas con poca participación en la cooperativa o el sindicato señalan que vinculan al sindicato como un sindicato de "izquierda", al defender el trabajo, pero no es tan clara la relación del sindicato y la cooperativa con un discurso o acciones frontalmente antineoliberales. Por su parte, las personas que tienen actividad en el sindicato y la cooperativa expresan que las artes escénicas que conocían han cambiado fruto de una noción 
general que se encuadra en una coyuntura política "neoliberal" pero sin referencias a las relaciones sociales estructuradas en torno a la producción. Y que, dentro del sindicato hay diferencias de militancia y tradiciones de izquierda disímiles marcadas por la dictadura como parteaguas de sus definiciones político-ideológicas, donde no es tan evidente una postura única que asocie claramente vanguardia artística con vanguardia política.

Resultado del sistema neoliberal- lo colectivo lo vuelve individual, que está pasando en las artes, ayer recontra comprometidas, hoy relativamente, lo son, si me va bien a mí. La gente empieza a trabajar solo si hay fondos, te hace siete obras en el año solo porque hay que hacerlas (Mujer, 56 años).

En unos pocos casos se menciona que las concepciones estéticas y el tipo de quehacer escénico que se practica son lo que determina una política y donde estaría la capacidad de expresar una crítica social. No es la forma de organización del trabajo o una identidad como "trabajador" lo que se expresa como disidencia frente al estado actual de relaciones. Sería la especificidad de la producción artística lo que determinaría la crítica, lo que Adorno entiende como el gesto transformador del arte, el "robarle al presente su justificación ideológica" (BUCK-MORSS, 2001, p.102)

De esta manera, en Valorarte se expresan desde diversas situaciones y acercamientos a la cooperativa la ambigüedad del quehacer artístico. Entre sus integrantes es la noción de trabajador un aglutinante para la acción colectiva y la posibilidad de reclamos de mejores condiciones de vida, aunque esta identidad no remita a una crítica directa o radical. Y entre los fundadores aparece la idea de que no es lo mismo ser una cooperativa que una sociedad anónima, pero hoy en día la cooperativa no es un claro motor de cambio.

Esto se liga con la percepción general de los entrevistados que la cooperativa tiene un carácter más instrumental que no llega a consolidar una identidad a la cual vincularse, con una institucionalización de la negociación sindical que no los convoca. De todos modos, en su rechazo a esa forma de entender el trabajo, no se llega a expresar una alternativa de reorganización crítica del trabajo y "un proceso de formación de agente transformador autónomo" (BERARDI, 2012, p.84). No hay una idea de vida o mundo radicalmente diferente, ni un hacer contra el trabajo, en tanto fuerza contra el capital. Hay un hacer no determinado por la idea de trabajo tradicional, de relación capital-trabajo. He ahí una fuerza, que no solo tiene que ver con su posible precarización y precariedad no elegida sino con un hacer que no necesita la seguridad de la institución "trabajo" para que exista y se legitime, así como tampoco las relaciones jerarquizadas y jerárquicas de los sindicatos tradicionales. Y 
valoran enormemente la capacidad de hacer teatro simplemente por la necesidad de hacerlo, que no responde a la crítica histórica de la defensa del trabajo, ni al artista como militante, sin por ello dejar de ser críticos con las condiciones sociales e institucionales de producción escénica y su necesidad de cambio.

Las artes escénicas como relación social son una experiencia estética y sensible compartida que produce significados. Y que, como actividad, organiza el trabajo con particularidades: es itinerante, por proyecto, con horarios dispares, sin continuidad, etc. Estas características vuelven conflictivas la identificación de sujetos políticos vinculados al trabajo escénico en su efectiva capacidad para la defensa de derechos colectivos y la crítica social. El artista como trabajador y las organizaciones colectivas que conforman deben hacer frente a las dificultades de defender el trabajo en las condiciones de producción y reorganización social posfordista.

\section{Bibliografia}

ASUAGA, C., LECUEDER, M, VIGO, S. Las Artes Escénicas y la Teoría General del Costo. En: IX CONGRESSO INTERNACIONAL DE CUSTOS, 2005, Florianópolis, SC, Brasil.

BUTLER J. Introducción. En: Estado de inseguridad. Gobernar la precariedad. Madrid: Traficantes de Sueños, 2016.

BAUDRILLARD, J. El espejo de la producción. Barcelona: Gedisa, 2000.

BERARDI, F. El alma y el trabajo. México: Elefanta del Sur, 2012.

BOLOGNA, S. Crisis de la clase media y posfordismo. Madrid: Akal, 2006.

BREA, J. L. El tercer Umbral. Estatuto de las prácticas artísticas en la era del capitalismo cultural. Murcia: CENDEAC, 2009.

BUCK-MORSS, S. Origen de la dialéctica negativa. Theodor W. Adorno, Walter Benjamin y el Instituto de Frankfurt. Buenos Aires: Eterna Cadencia, 2011.

CASTELLS, M. La era de la información. Economía, sociedad y cultura. Buenos Aires: Siglo XXI, 1996.

COLLAZO, M. Seguridad social del artista. En Derechos sociales de los artistas, París: Unesco, 2004.

DURÁN, J. El valor de la obra de arte desde una perspectiva marxista. Ensayos de economía, Bogotá, n 40, Enero-Junio, p. 205-217, 2012.

DURÁN, J (2014) Arte y Capital. Releyendo el capítulo VI (inédito) de "El Capital". Consultado en http://informecapital.net/revista/?page_id=128, 8/7/20 
ETCHEVERRY, S., ROMERO, M., y TORRELLI, M. 10 años de las Cooperativas de artistas en Uruguay. Naturaleza, funcionamiento y perspectivas. Montevideo: INACOOP, 2018.

EXPÓSITO, M. Introducción. En: Producción cultural y prácticas instituyentes. Líneas de ruptura en la crítica institucional. Madrid: Traficantes de sueños, 2008, p. 15-23.

FEREGRINO, A. La reglamentación y los "trabajos especiales". Una mirada desde un paradigma complejo. Argumentos, septiembre-diciembre, p. 95-122, 2011.

GARCÍA LÓPEZ, J. LAGO BLASCO, J., MESEGUER, P., y RIESCO, A. Prefacio. En B. R. Lahire, Lo que el trabajo esconde. Materiales para un replanteamiento de los análisis sobre el trabajo. Madrid: Traficante de Sueños, p.13-18, 2005.

HERNÁNDEZ-BEJARANO, M. Nuevos modelos de cooperativas de trabajos autónomos: un análisis de las cooperativas de impulso empresarial y las cooperativas de facturación. Economia colaborativa y trabajo en plataforma: realidades y desafíos, p. 145-185, 2017.

HOLlOWAY, J. Agrietar el capitalismo. El hacer contra el trabajo. Buenos Aires: Herramienta, 2011.

INFANTINO, J. Trabajar como artista. Estrategias, prácticas y representaciones del trabajo artístico entre jóvenes artistas circenses. Cuadernos de Antropología Social n.34, p.141 -163, 2011.

JAUSS, H. Pequeña apología de la experiencia estética. Buenos Aires: Paidós, 2002.

LAZZARATO, M. Las miserias de la "crítica artística" y del empleo cultural. En Producción cultural y prácticas instituyentes Líneas de ruptura en la crítica institucional. Madrid: Traficante de sueños, p.101-120, 2008.

LAZZARATO, M. Marcel Duchamp y el rechazo del trabajo. Seguido de la Miseria de la Sociología. Madrid: Casus-Belli, 2015.

LÓPEZ CUENCA, A. Los comunes digitales: nuevas ecologías del trabajo artístico. Ciudad de México: Remediables, 2016.

LOREY, I. Gubernamentalidad y precarización de sí. Sobre la normalización de los productores y las productoras culturales. En Producción cultural y prácticas instituyentes. Líneas de ruptura en la crítica institucional. Madrid: Traficantes de Sueños, p. 57-78, 2008.

LOREY, I. Estado de inseguridad. Gobernar la precariedad. Madrid: Traficantes de Sueños, 2016.

MAURO, K. Identidades y apelaciones antagónicas de los trabajadores del espectáculo (19021955). Telóndefondo n. 27, v. 14 (enero-junio) p.176-231, 2018.

MAURO, K. Trabajo asociativo y actuación: las cooperativas de teatrales y la gratuidad crónica del trabajo actoral. XI Jornadas de Sociología. Facultad de Ciencias Sociales, Universidad de Buenos Aires, Buenos Aires, 2015. 
MARTÍ, J, SORIA, C, DABEZIES, MJ. (2007). Programas públicos para el fomento del cooperativismo de trabajo en Uruguay (1976-2006) Políticas Públicas de fomento del cooperativismo de trabajo en el Cono Sur. Montevideo: Red Unircoop.

MILLER, T. El trabajo cultural. Barcelona: Gedisa, 2018.

MOLANO, M. Desafíos para una teoría del arte: experiencia estética, institución y función social. AISTHESIS n.51, p.79-92, 2012.

MOULIER BOUNTAN, Y. Capitalismo Cognitivo, propiedad intelectual y creación colectiva. Madrid: Traficante de Sueños, 2004.

NEGRI, A. Marx y el trabajo: el camino de la disutopía. En: GUATTARI, F., y NEGRI, T. Las verdades nómadas y General Intellect, poder constituyente, comunismo. Madrid: Akal, 1999, p. 125-139.

REMEDI, G. Agendas de fuga: Teatro, sociedad y política. Estudios del teatro uruguayo contemporáneo. En V. L. Proaño Gómez Lola, Perspectivas políticas de la escena latinoamericana. Diálogos en tiempo presente. Buenos Aires: Argus, 2017, p. 75-108.

ROWAN, J. Cultura libre de Estado. Madrid: Traficantes de Sueños, 2016.

SÁNCHEZ VÁZQUEZ, A. Estética y Marxismo. Ciudad de México: Era, 1975.

VIRNO, P. Gramática de la multitud. Madrid: Traficantes de Sueños, 2003. 